\title{
RECRYSTALLIZED PARYLENE AS A MASK FOR SILICON CHEMICAL ETCHING
}

\author{
Hsi-wen $\mathrm{Lo}^{1}$, Wen-Cheng Kuo ${ }^{1,2}$, Yao-Joe Yang ${ }^{2}$, and Yu-Chong Tai ${ }^{1}$ \\ ${ }^{I}$ Department of Electrical Engineering, California Institute of Technology, USA \\ ${ }^{2}$ Department of Mechanical Engineering, National Taiwan University, Taiwan
}

\begin{abstract}
This paper presents the first use of recrystallized parylene as masking material for silicon chemical etch. Recrystallized parylene was obtained by melting parylene $\mathrm{C}$ at $350{ }^{\circ} \mathrm{C}$ for 2 hours. The masking ability of recrystallized parylene was tested in HNA (hydrofluoric acid, nitric acid and acetic acid) solution of various ratios, KOH (potassium hydroxide) solution and TMAH (tetramethylammonium hydroxide) at different temperatures and concentrations. It is found that interface between parylene and the substrate can be attacked, which results in undercuts. Otherwise, recrystallized parylene exhibited good adhesion to silicon, complete protection of unexposed silicon and silicon etching rates comparable to literature data.
\end{abstract}

Keywords- parylene; silicon wet etching; recrystallization;

\section{INTRODUCTION}

Silicon wet etching processes are applied in fabrications of traditional MEMS structures, such as silicon cantilevers, silicon thin diaphragms, and other freestanding structures. Although inductively-coupled plasma etching, or deep reactive ion etching (DRIE) can achieve high aspect ratio structures, silicon wet etching provides relatively cheap, simple and easy processes and remain indispensable in MEMS fields.

The common masks used in silicon wet etchings, such as TMAH and $\mathrm{KOH}$ are silicon oxides and silicon nitrides. Silicon oxides can be obtained by LPCVD, PECVD or thermal oxidation and silicon nitrides is obtained through LPCVD and PECVD. These deposition processes somehow add additional complexity and design challenges to the overall processes. Thermal oxidation and LPCVD processes require high temperature and thus cause stress problems in the deposited thin film while PECVD oxide and nitrides can be etched at a considerable rate by silicon wet etchants. Sometimes, using hard masks is simply impossible since deposition of hard masks will inevitably damage the existing microstructures.

To address problems aforementioned, polymeric mask materials have been developed [1][2]. Polymeric masks emerge as easy and economical alternatives to hard masks and provide fair protection and pattern-transferring capabilities.

Parylene, or poly(paraxylylene), has been widely used in many MEMS application. Microfluidic channels [3], electrospray inject nozzles [3], pressure sensors [4], implantable electrode arrays [5], and etc. have been demonstrated.

Tooker and Tai first reported using recrystallized parylene $\mathrm{C}$ to improve the adhesion between parylene $\mathrm{C}$ and glass slides
[6]. Parylene $\mathrm{C}$ was heated at $350^{\circ} \mathrm{C}$ in nitrogen ambient and was melted and recrystallized. Recrystallized parylene $\mathrm{C}$ provides much stronger adhesion to glass and can still be etched by oxygen plasma [6]. This paper then explores the capability of recrystallized parylene $\mathrm{C}$ as the etching masks for silicon etching.

\section{EXPERIMENTAL DETAILS}

\section{A. Sample Preparation}

All samples are prepared in the same way. It starts with prime silicon wafers, be it double-side polished or single-side polished. Silicon wafers are first cleaned isopropyl alcohol and acetone. Next, wafers are cleaned with standard piranha solution to fully remove organic contamination. Prior to parylene deposition, wafers are dipped in $5 \mathrm{wt} \%$ hydrofluoric acid to clean the surface and to remove silicon dioxides.

Parylene $\mathrm{C}$ of different thickness is then deposited on silicon wafers via a room-temperature chemical vapor deposition (CVD) process. Thickness of parylene is controlled by the amount of dimmer weight loaded in the machine. All parylene dimmers are used as purchased from Specialty Coating Systems. No further purification is performed. After parylene deposition, wafers with parylene are heated in a furnace filled with nitrogen. The temporal heating profile of the furnace is such that it ramps up to the hold temperature, $350^{\circ} \mathrm{C}$ at a rate of $10^{\circ} \mathrm{C}$ per minute and maintains the hold temperature, $350^{\circ} \mathrm{C}$, for 2 hours and finally cools down to room temperature naturally (the ramp down rate is less than $2{ }^{\circ} \mathrm{C}$ per minute. The hold temperature, $350^{\circ} \mathrm{C}$, and 2 hours of hold time are selected so as to ensure parylene $\mathrm{C}$ is fully melted and recrystallized.

After parylene $\mathrm{C}$ is recrystallized, etching windows are opened with conventional photolithography process and reactive ion etching (RIE) oxygen plasma etching. Here, it is worth note that recrystallized parylene $\mathrm{C}$ has a slower etching rate than generic parylene $\mathrm{C}$, typically around 0.5 times of that of generic parylene $\mathrm{C}$.

After etching windows and patterns are formed, recrystallized parylene $\mathrm{C}$ coated silicon wafer samples are dipped into various silicon etching solutions

\section{B. Etching Solution Preparation}

Tetramethylammonium hydroxide (TMAH) solutions are prepared by diluting TMAH 25 wt \% solution, purchased from Sigma Aldrich, with deionized (DI) water. Similarly,

*Contact author: Hsi-wen Lo, Caltech Micromachining Group, 1200 E. California Blvd, Pasadena, CA, 91125, USA, email: lo@mems.caltech.edu. 


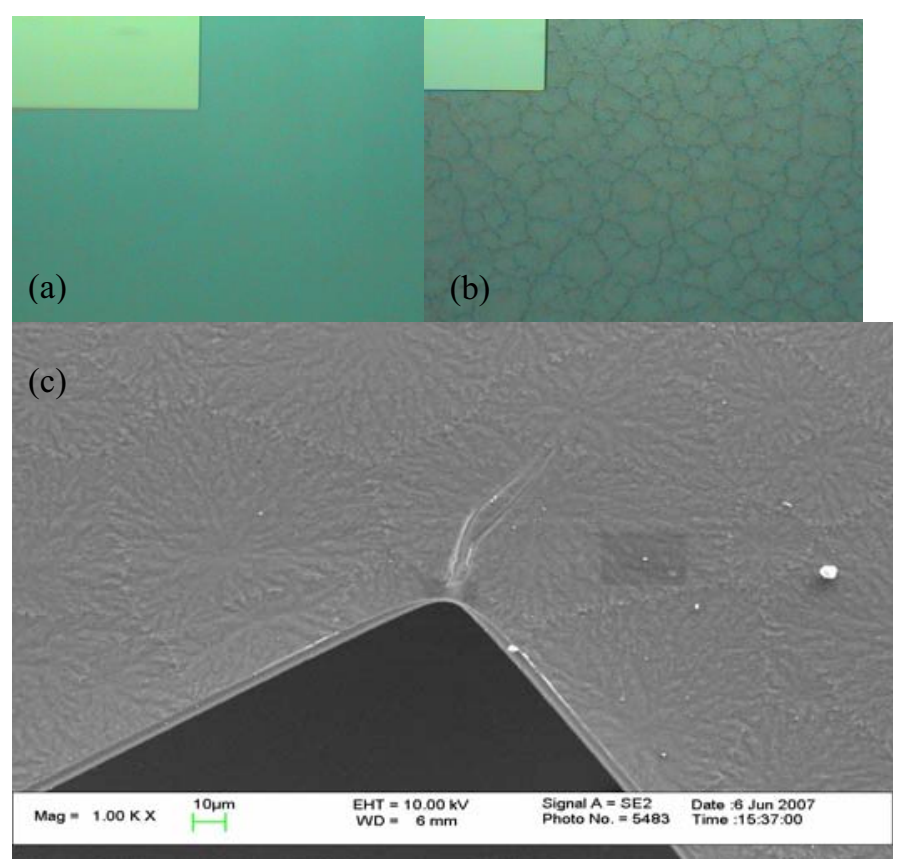

Figure 1. Parylene surfaces: Polarized green optical microscopic picture before recrystallization (a), and after recrystallization (b). (c) is the SEM pictures of recrystallized parylene. Grain diameters in (b) are around $200 \mu \mathrm{m}$.

Potassium hydroxide $(\mathrm{KOH})$ solutions are prepared by diluted $\mathrm{KOH}$ solution $45 \mathrm{wt} \%$ solutions, purchased from Sigma Aldrich, with DI water. Hydrofluoric acid - nitric acid - acetic acid (HNA) etching systems are prepared by mixing $49 \%$ hydrofluoric acid, 98\% nitric acid and anhydrous acetic acid at different ratio.

Reflux systems are used for TMAH and $\mathrm{KOH}$ etching processes.

\section{Measurement Methods and Instrument}

The undercut length is measured under optical microscopes and the etching depth is measured with KLA Tencor P15 surface profilometer. Scanning electron microscopy (SEM) is also used to further identify surface properties of recrystallized parylene and cross-sectional structures of silicon after etching.

\section{RESULTS AND DISCUSSION}

Recrystallized parylene $\mathrm{C}$ has polycrystalline structures. Different from generic parylene $\mathrm{C}$, grain boundary can be easily and clearly observed under optical microscopes, especially when using optical microscopes with polarized light sources. Fig. 1 shows the pictures of generic and recrystallized parylene under polarized green microscopes and SEM pictures of recrystallized parylene surfaces.

As can be seen from Fig. 1, grain boundaries appeared after baking generic parylene $\mathrm{C}$ at $350^{\circ} \mathrm{C}$ for 2 hours and crystallized did occur in the heating processes. That is why we call parylene $\mathrm{C}$ after the heat treatment "recrystallized parylene".

To assess whether recrystallized parylene $\mathrm{C}$ is a reliable silicon etching mask, several issues have to be investigated. Among these, crucial question such as how thick parylene should be to provide decent protection, what the undercut rate is, if any, and what is etching selectivity with respect to silicon will be addressed in this paper. Several experiments are performed to answer these questions.

\section{A. Selectivity}

Typical silicon wet etchants are KOH, TMAH and HNA. There is no known chemical reaction between parylene and these silicon etchants, and we can surely assume parylene will not be damaged during etching processes. Later experiments confirmed this claim. The selectivity of silicon with respect to parylene is, therefore, infinity. That makes recrystallized parylene an excellent mask for silicon wet etching.

\section{B. Thickness}

Thickness of parylene reduces less than 5\% after recrystallization. Since the change is small, thicknesses discussed in this paper hereafter are all the thickness of parylene before recrystallization.

Three samples of silicon wafers are prepared to answer this

(a)

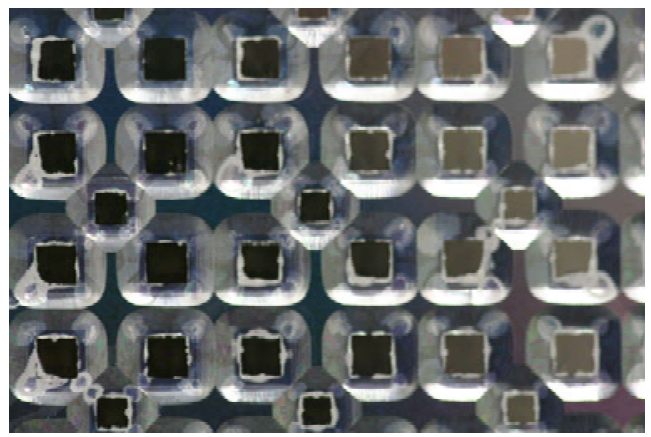

(b)

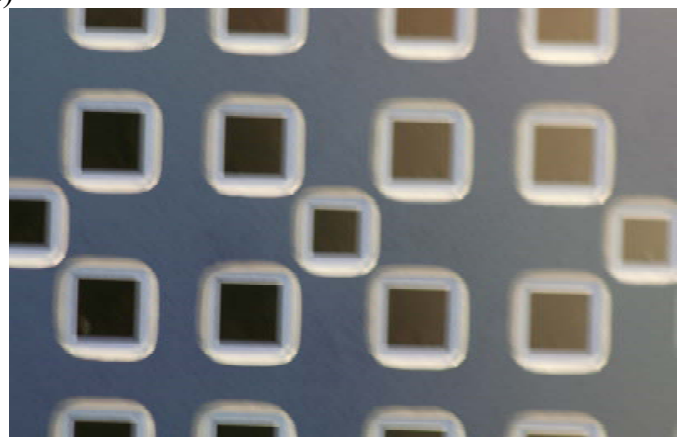

(c)

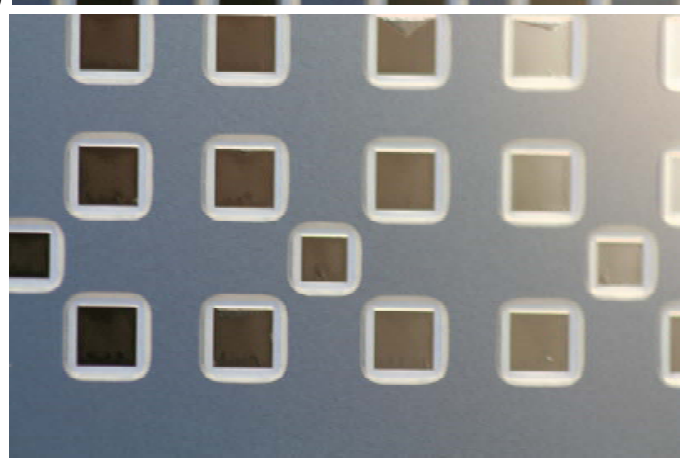

Figure 2. Recrystallized parylene samples after 9 hours in $58{ }^{\circ} \mathrm{C} \mathrm{KOH}$ (a) $1 \mu \mathrm{m}$, (b) $2.5 \mu \mathrm{m}$, and (c) $5 \mu \mathrm{m}$. Serious undercuts occur in (a). 
question. The thicknesses of these three samples are $1 \mu \mathrm{m}$, $2.5 \mu \mathrm{m}$, and $5 \mu \mathrm{m}$. These samples are dipped in $20 \% \mathrm{KOH}$ solutions at $58{ }^{\circ} \mathrm{C}$ for 9 hours. Fig. 2 shows the pictures of these three samples after etching.

As shown in Fig. 2, 1- $\mu \mathrm{m}$ recrystallized parylene renders serious undercuts and poor pattern transferring ability while 5$\mu \mathrm{m}$ recrystallized parylene gives satisfactory results both for undercuts and pattern transferring. It follows that the thicker parylene is, the better etch-masking ability it provides. However, time and effort to pattern recrystallized parylene increases as the parylene thickness increase and the etching rate of recystallized parylene is, for the same oxygen plasma etching conditions, half as much as that of generic parylene. In determining proper parylene thickness, one has to balance masking ability and the time to patterning it. $5-\mu \mathrm{m}$ recrystallized parylene was chosen in the experiments determining undercut rates.

\section{Single-Side Polished and Double-Side Polished Wafers}

In the previous experiment determining the proper thickness of recrystallized parylene, single-side polished (SSP) wafers were used. Serious delimination of recrystallized parylene and therefore undesired etching and damages always occurred on the backside even when recrystallized parylene is thick enough to provide protections on the front side. Based on this fact, double-side polished (DSP) wafers are used for following experiment.

\section{Undercuts}

The most important two specifications of a wet-etching mask are selectivity and undercut rates. For recrystallized parylene as silicon etching masks, only undercut rates have to be addressed, since the silicon wet etchants do not react with recrystallized parylene. Mask pattern designers have to take into consideration the undercut rates of recrystallized parylene when they choose recrystallized parylene as the etching masks.

Here the undercut rate is defined by the ratio of the undercut length divided by total etching time. The undercut length is the distance from the start of parylene delamination to the edge of the etching openings, as shown in Fig. 3.

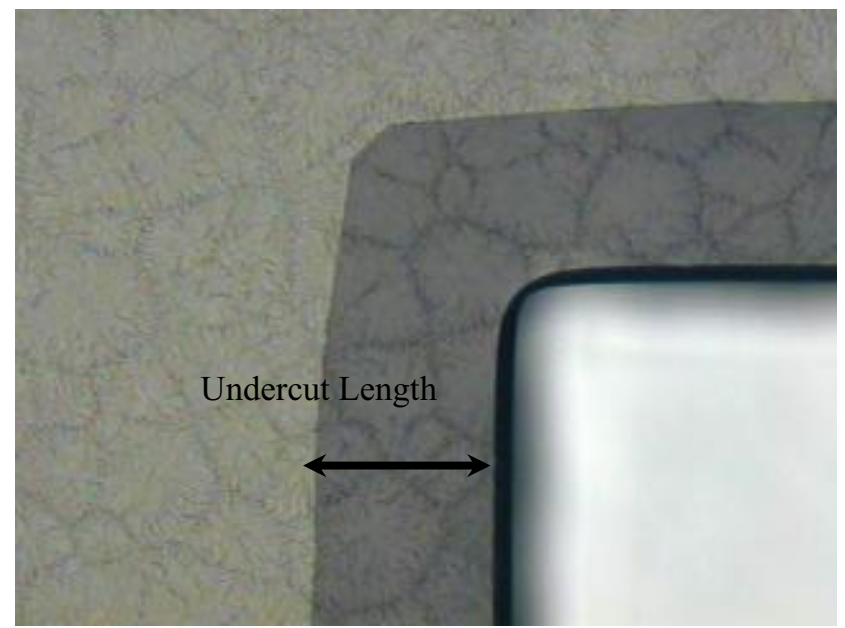

Figure 3. Undercut length defintion. For this picture, the undercut legnth is $125 \mu \mathrm{m}$
TABLE I. KOH ETCHING SYSTEMS

\begin{tabular}{|l|l|l|l|}
\hline $\begin{array}{c}\text { KOH } \\
\mathbf{W t} \%\end{array}$ & $\begin{array}{c}\text { Temperature } \\
\left({ }^{\circ} \mathrm{C}\right)\end{array}$ & $\begin{array}{c}\text { Silicon etching rate } \\
(\mu \mathbf{~ m} / \mathbf{h r})\end{array}$ & $\begin{array}{c}\text { Undercut rate } \\
(\mu \mathbf{~ m} / \mathbf{h r})\end{array}$ \\
\hline 20 & 50 & 9.35 & 25 \\
\hline 20 & 60 & 17.8 & 55 \\
\hline 20 & 70 & 30 & 141 \\
\hline 30 & 50 & 10.5 & 25 \\
\hline 30 & 60 & 26.5 & 56.3 \\
\hline 30 & 70 & 49 & 230 \\
\hline 40 & 50 & 9 & 27.5 \\
\hline 40 & 60 & 25 & 122.5 \\
\hline 40 & 70 & 33 & 110 \\
\hline
\end{tabular}

TABLE II. TMAH ETCHING SYSTEMS

\begin{tabular}{|l|l|l|l|}
\hline $\begin{array}{c}\text { TMAH } \\
\mathbf{W t} \%\end{array}$ & $\begin{array}{c}\text { Temperature } \\
\left({ }^{\circ} \mathrm{C}\right)\end{array}$ & $\begin{array}{c}\text { Silicon etching rate } \\
(\mu \mathbf{~ m} / \mathbf{h r})\end{array}$ & $\begin{array}{l}\text { Undercut rate } \\
(\mu \mathbf{~ m} / \mathbf{h r})\end{array}$ \\
\hline 10 & 70 & 19.995 & 15 \\
\hline 10 & 80 & 33.36 & 30.5 \\
\hline 10 & 90 & 36.19 & 44 \\
\hline 15 & 70 & 17.942 & 15.5 \\
\hline 15 & 80 & 29.81 & 55 \\
\hline 15 & 90 & 43.31 & 50 \\
\hline 20 & 70 & 15.73 & 13 \\
\hline 20 & 80 & 23.354 & 32 \\
\hline 20 & 90 & 38.204 & 67.05 \\
\hline 25 & 70 & 11.798 & 13 \\
\hline 25 & 80 & 22.053 & 41 \\
\hline 25 & 90 & 40.929 & 65 \\
\hline
\end{tabular}

TABLE III. HNA ETCHING SYSTEMS

\begin{tabular}{|c|c|c|c|c|}
\hline \multicolumn{3}{|c|}{ Weight Percentages (\%) } & \multirow{2}{*}{$\begin{array}{l}\text { Silicon etching rate } \\
\qquad(\mu \mathrm{m} / \mathrm{min})\end{array}$} & \multirow{2}{*}{$\begin{array}{l}\text { Undercut rate } \\
(\mu \mathrm{m} / \mathbf{m i n})\end{array}$} \\
\hline$H F$ & $\mathrm{HNO}_{3}$ & $\mathrm{HCH}_{3} \mathrm{COOH}$ & & \\
\hline 10 & 60 & 30 & 2.5 & 2.5 \\
\hline 10 & 70 & 20 & 4.3 & 3.4 \\
\hline 10 & 80 & 10 & 2.65 & 2 \\
\hline 20 & 50 & 30 & 7.2 & 6.67 \\
\hline 20 & 60 & 20 & 6.5 & 6 \\
\hline 20 & 70 & 10 & 7.2 & 5.4 \\
\hline 30 & 30 & 40 & 18.9 & 20.3 \\
\hline 30 & 40 & 30 & 9 & 11.3 \\
\hline 30 & 50 & 20 & 11.7 & 9.5 \\
\hline 30 & 60 & 10 & 10.316 & 9.16 \\
\hline 40 & 20 & 40 & 30.6 & 51.7 \\
\hline 40 & 30 & 30 & 54.3 & 107 \\
\hline 40 & 40 & 20 & 35.7 & 33.3 \\
\hline 50 & 10 & 40 & 22.5 & 21.7 \\
\hline 50 & 20 & 30 & 59.4 & 113.3 \\
\hline 50 & 30 & 20 & 76 & 132.3 \\
\hline 50 & 40 & 10 & 43.76 & 95.8 \\
\hline 60 & 10 & 30 & 29.85 & 27.5 \\
\hline 60 & 20 & 20 & 48.5 & 56.25 \\
\hline 60 & 30 & 10 & 50.625 & 75 \\
\hline 70 & 10 & 20 & 36.6 & 32.22 \\
\hline 70 & 20 & 10 & 61.3 & 53.93 \\
\hline
\end{tabular}




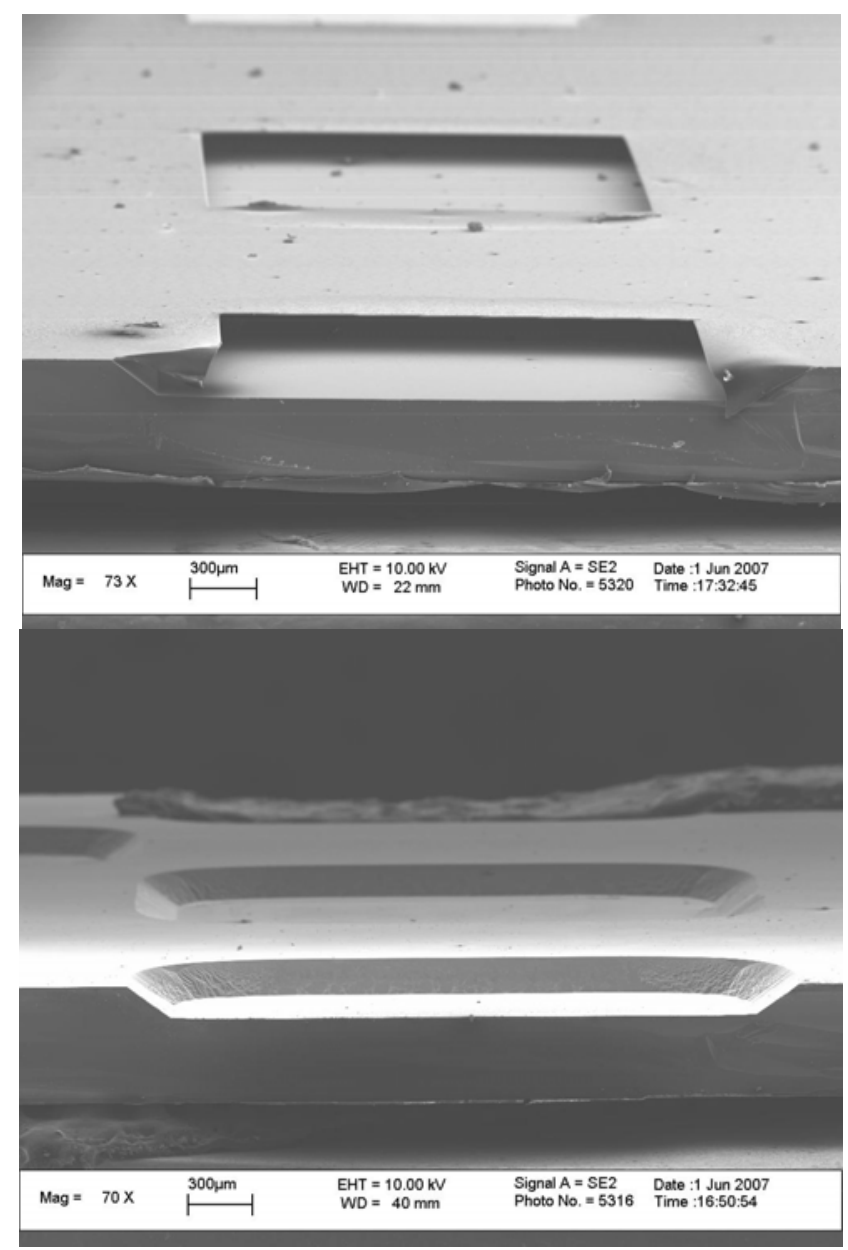

Figure 4. SEM pictures before (top) and after (bottom) removing recrystallized parylene

Table I, II, and III list silicon undercut rates of recrystallized parylene for $\mathrm{KOH}$ solutions of concentrations from $20 \%$ to $40 \%$ and temperatures from $50{ }^{\circ} \mathrm{C}$ to $70{ }^{\circ} \mathrm{C}$, TMAH solutions of concentrations from $10 \%$ to $25 \%$ and temperatures from $70^{\circ} \mathrm{C}$ to $90^{\circ} \mathrm{C}$, and HNA etching systems of various composition ratios. All samples use $5 \mu \mathrm{m}$ recrystallized parylene as the mask.

Through comparison of undercut rates and silicon etch rates for TMAH and $\mathrm{KOH}$, we fond that undercuts result from etchant attacking interfaces between parylene and silicon. Undercut rate should be smaller than silicon etching rate for $\mathrm{TMAH}$ and $\mathrm{KOH}$ since these two etching systems are anisotropic. Unlike hard masks materials such as thermal oxide, adhesion between parylene and silicon is less chemical bonding than mechanical adhesion. Although recrystallization process improves parylene adhesion to silicon, the adhesion is still within Van Der Waals force range. To further improve the masking ability of recrystallized parylene $\mathrm{C}$ requires strengthening the adhesion between parylene and silicon. However, we haven't, so far, found any other way as effective as recrystallization of parylene. While undercuts are inevitable, designers can take undercut rates into consideration when they design and determine mask patterns.

After etching, the recrystallized parylene can be removed by oxygen plasma. Fig. 4 shows the SEM pictures of the silicon sample before and after removing recrystallized parylene.

\section{CONCLUSION}

We demonstrated using recrystallized parylene as the mask for silicon wet etching. Parylene $\mathrm{C}$ is recrystallized after heating at $350{ }^{\circ} \mathrm{C}$ for 2 hours in nitrogen ambient. The thickness required to provide decent protection and undercut rates for $\mathrm{KOH}$, TMAH and HNA etching systems are determined. After etching, recrystallized parylene can be removed with oxygen plasma. Recrystallized parylene provides a simple and economical alternative to conventional hard mask materials for silicon wet etching.

\section{ACKNOWLEDGMENT}

The authors thank all members from Caltech Micromachining Laboratory for their assistance on design, fabrication and testing.

\section{REFERENCES}

[1] K. Ruben, T. Flaim, and C. Li, "Polymer Protective Coatings for MEMS Wet-Etch Processes" Proc. of SPIE, vol 5342, 2004.

[2] G. Ganavese, S. L. Marasso, M. Quaglio, M. Cocuzza, C. Ricciardi, and C. F. Pirri, "Polymer mask protection for alternative KOH silicon wet etching” J. Micromechanics and Microengineering, 17(2007) pp 13871393.

[3] Q. He, Y. Miao, T. Lee and Y. C. Tai, "An Integrated Microchip With Conventionally-Packed Liquid Chromotography Column and Electrospray Ionization Nozzle for LC-ESI-MS Applications”, Proc. Of MSB'05, 2005

[4] P.J. Chen, D. Rodger, M. Humayun and Y. C. Tai, "Spiral-Tube Parylene Intraocular Pressure Sensor", Proc of MEMS'05, 2005

[5] D. C. Rodger, W. Li, H. Ameri, A. Ray, J. D. Weiland, M.S. Humayun and Y. C. Tai, "Flexible Parylene-Based Microelectrode Technology for Intraocular Retinal Prostheses", Proc of IEEE-NEMS'06, 2006

[6] A. Tooker, Ph. D. Thesis, California Institute of Technology, 2007

[7] B. Schwartz and H. Robbins, "Chemical Etching of Silicon", J. Eletrochem. Soc, Vol 123, No 12, 1976

[8] H. Seidel, L. Csepregi, A. Heuberger and H. Baumgartel, "The Mechanism Anisotropic Silicon Etching and Its Relevance for Micromachining", Proc. of Transducer'87, 1987 